\title{
A Clinical Tool to Predict Low Serum Selenium in Patients with Worsening Heart Failure
}

\author{
Ali A. Al-Mubarak ${ }^{1}$, Niels Grote Beverborg ${ }^{1}$, Stefan D. Anker ${ }^{2}$, Nilesh J. Samani ${ }^{3,4}$, \\ Kenneth Dickstein ${ }^{5,6}$, Gerasimos Filippatos ${ }^{7}$, Dirk Jan van Veldhuisen ${ }^{1}$, Adriaan A. Voors ${ }^{1}$, \\ Nils Bomer $1, *,+(\mathbb{D})$ and Peter van der Meer ${ }^{1, *,+}$ \\ 1 Department of Cardiology, University Medical Center Groningen, University of Groningen, 9700 RB \\ Groningen, The Netherlands; a.al.mubarak@umcg.nl (A.A.A.-M.); n.grote.beverborg@umcg.nl (N.G.B.); \\ d.j.van.veldhuisen@umcg.nl (D.J.v.V.); a.a.voors@umcg.nl (A.A.V.) \\ 2 Innovative Clinical Trials, Department of Cardiology and Pneumology, University Medical Centre \\ Göttingen (UMG), 37075 Göttingen, Germany; s.anker@cachexia.de \\ 3 Department of Cardiovascular Sciences, University of Leicester, Leicester LE39QP, UK; njs@leicester.ac.uk \\ 4 NIHR Leicester Biomedical Research Centre, Glenfield Hospital, Leicester LE39QP, UK \\ 5 Stavanger University Hospital, 4011 Stavanger, Norway; trout@online.no \\ 6 Department of Clinical Science, University of Bergen, 5007 Bergen, Norway \\ 7 Department of Cardiology, Heart Failure Unit, Athens University Hospital Attikon, 12406 Athens, Greece; \\ geros@otenet.gr \\ * $\quad$ Correspondence: n.bomer@umcg.nl (N.B.); p.van.der.meer@umcg.nl (P.v.d.M.); Tel.: +31-50-361-7106 (N.B.) \\ + These authors share senior authorship.
}

Received: 29 May 2020; Accepted: 17 August 2020; Published: 21 August 2020

check for updates

\begin{abstract}
Selenium is an essential micronutrient, and a low selenium concentration $(<100 \mu \mathrm{g} / \mathrm{L})$ is associated with a poorer quality of life and exercise capacity, and an impaired prognosis in patients with worsening heart failure. Measuring selenium concentrations routinely is laborious and costly, and although its clinical utility is yet to be proven, an easy implemented model to predict selenium status is desirable. A stepwise multivariable logistic regression analysis was performed using routinely measured clinical factors. Low selenium was independently predicted by: older age, lower serum albumin, higher N-terminal pro-B-type natriuretic peptide levels, worse kidney function, and the presence of orthopnea and iron deficiency. A 10-points risk-model was developed, and a score of $\geq 6$ points identified $>80 \%$ of patients with low selenium (sensitivity of $44 \%$, specificity of $80 \%$ ). Given that selenium and iron overlap in their physiological roles, we evaluated the shared determinants and prognostic associates. Both deficiencies shared similar clinical characteristics, including the model risk factors and, in addition, a low protein intake and high levels of C-reactive protein. Low selenium was associated with a similar or worse prognosis compared to iron deficiency. In conclusion, although it is difficult to exclude low selenium based on clinical characteristics alone, we provide a prediction tool which identifies heart failure patients at higher risk of having a low selenium status.
\end{abstract}

Keywords: selenium; malnutrition; heart failure; albumin; iron deficiency

\section{Introduction}

Heart failure (HF) is a clinical syndrome resulting from impaired ventricular filling or the ejection of blood. HF accounts for substantial morbidity and mortality, with increasing prevalence globally [1]. Various factors play a causative role in developing HF, including myocardial infarction, hypertension, diabetes, and valvular heart diseases [1]. Moreover, in the last decade micronutrient deficiencies have been implicated in the development and progression of HF [2]. An aberrant equilibrium of minerals and trace elements (for example, iron, iodine, and zinc) in patients' circulation is closely associated with 
the development and progression of HF [3,4]. Up to $50 \%$ of patients with HF suffer from some form of malnutrition, such as micronutrient insufficiencies [5,6]. A deficiency in the trace element iron was associated with decreased cardiomyocyte contractility and increased morbidity and mortality [7-9], whereas treatment with intravenous iron has been shown to relieve symptoms [10-12]. Phase III clinical trials with the aim of improving patient prognosis are currently being conducted (NCT02937454) [13].

Selenium (Se) is an essential micronutrient which has been less intensively studied though previous studies, suggesting that very severe deficiency in humans is associated with cardiomyopathy (Keshan disease) [3,14]. Recently, we showed that approximately $25 \%$ of patients with worsening HF have a serum $\mathrm{Se}<70 \mu \mathrm{g} / \mathrm{L}$, and that this was associated with a poorer quality of life, poor exercise capacity, and a worse prognosis [15]. Furthermore, a serum Se concentration of 70-100 $\mu \mathrm{g} / \mathrm{L}$ appeared to have similar adverse associations, suggesting that values $<100 \mu \mathrm{g} / \mathrm{L}$ might be considered insufficient for the physiological requirement and thus abnormal [16,17]. The supplementation of Se is relatively simple and safe, but its clinical utility has yet to be proven. However, since Se is not measured routinely in clinics due to the labor intensity and subsequent high costs, identifying patients with a low Se is challenging. Furthermore, Se and iron share several physiological functions, such as redox homeostasis [3,9], angiogenesis [18], and immune response [3,9]. Nevertheless, the effects of the potential shared risk factors and interactions between both deficiencies on the prognosis of HF patients are not known.

In this study, we used the clinical predictors of a low serum Se concentration $(<100 \mu \mathrm{g} / \mathrm{L})$ in patients with worsening HF to develop a model capable of predicting the presence of a low Se level. Such a model will provide insights of the clinical factors related to Se and could improve the selection of patients that might benefit from Se supplementation, although this needs to be evaluated in clinical trials. In addition, we studied the levels of both Se and iron in association with the identified clinical predictors. Finally, we investigated the associations of Se and iron with prognosis independent from each other in established risk-models.

\section{Materials and Methods}

\subsection{Study Population}

We used data from the BIOSTAT-CHF index cohort (a systems BIOlogy Study to TAilored Treatment in Chronic Heart Failure), which has been described previously $[19,20]$. In short, BIOSTAT-CHF is a European cohort consisting originally of 2516 patients from 69 centers in 11 European countries. The included patients had to be 18 years old or older, with symptoms of new-onset or worsening HF. Their cardiac function has to be characterized by at least one of the following: a left ventricular ejection fraction (LVEF) of $\leq 40 \%$, a plasma B-type natriuretic peptide (BNP) of $>400 \mathrm{pg} / \mathrm{mL}$, or a plasma $\mathrm{N}$-terminal pro-B-type natriuretic peptide (NT-proBNP) of $>2000 \mathrm{pg} / \mathrm{mL}$. In addition, patients could only be included if they were sub-optimally treated for $\mathrm{HF}$ at inclusion (i.e., $\leq 50 \%$ of angiotensin-converting enzyme inhibitors, angiotensin receptor blockers, and/or beta-blockers). Patients with sepsis, acute myocarditis, or monogenic cardiomyopathy were excluded. The study was conducted in consensus with the Declaration of Helsinki. Informed consent was obtained from all the participants prior to any study-related activities.

\subsection{Laboratory Measurements and Related Definitions}

Blood samples were collected during the index hospitalization or at the outpatient clinic. Approximately $80 \mathrm{~mL}$ of blood plasma and serum were collected and stored at $-80^{\circ} \mathrm{C}$. The serum Se was measured using the validated inductively coupled plasma mass spectrometry (ICP-MS) method, as described previously [15]. A low serum Se concentration was set at serum levels of below $100 \mu \mathrm{g} / \mathrm{L}$ based on previous observations in patients with worsening HF [15]. The serum NT-proBNP concentrations were measured using an immunoassay based on electrochemiluminescence (Elecsys, Roche Diagnostics, Mannheim, Germany). Kidney function was calculated using the Modification 
of Diet in Renal Disease (MDRD) equation. Anemia was defined according to the WHO standards (hemoglobin level $<12 \mathrm{~g} / \mathrm{dL}$ in women and $<13 \mathrm{~g} / \mathrm{dL}$ in men). The iron-related parameters were measured as described previously by van der Wal et al. [9], and iron deficiency (ID) was defined as a transferrin saturation (TSAT) $<20 \%[7,21]$. HF with reduced ejection fraction (HFrEF) was defined as a left ventricular ejection fraction $<40 \%$.

\subsection{Statistical Analysis}

\subsubsection{Baseline Characteristics}

All the statistical analyses were performed using Stata v.16 SE and Weka v.3.6.15. The patients were divided into two groups based on their Se status (low Se $(<100 \mu \mathrm{g} / \mathrm{L})$ vs. normal Se $(\geq 100 \mu \mathrm{g} / \mathrm{L})$ ). Variables with a normal distribution were presented as a mean (standard deviation), while continuous variables with a non-normal distribution were presented as a median (interquartile range), and categorical variables were presented as a count (percentage). The baseline characteristics were analyzed using a t-test for continuous variables with a normal distribution, the Mann-Whitney $U$ test for continuous variables with skewed data, and the Chi-square test for categorical variables.

\subsubsection{Clinical Predictors of Low Se}

To identify independent predictors of low Se, a stepwise multivariable logistic regression analysis was performed. The potential determinants that can enter this analysis had to fulfill the following criteria: (i) a significant difference between the stratified groups in the baseline table, (ii) the potential predictor had to be used/measured/obtained routinely in the clinical practice, and (iii) the potential determinant should not have missing values $>15 \%$. If two biologically similar variables fulfilled these criteria (i.e., hemoglobin and anemia), only one variable was included in the analysis. The variables fulfilling these criteria are summarized in Table A1. After the stepwise regression, a multivariable logistic regression was performed on the selected variables to accurately establish their association with Se in the entire cohort. As a sensitivity analysis, a multivariable Lasso logistic regression model as well as a bootstrap analysis were performed, using the "Lasso" and "swboot" packages in Stata. The multicollinearity of the final model was checked by calculating the variance inflation factor, the values of which should not exceed a maximum of 10 [22].

\subsubsection{Prediction Model}

The optimal cutoff values for the independent predictors were determined using the unsupervised discretization tool in Weka [23]. Three not necessarily equal clusters were formed per continuous variable, the cutoff values of which were used to establish a risk-model. Two points were given to the values that favor low Se concentration the most, 1 point to the middle values, and 0 point to the remaining group. After determining the number of patients matching each score, the Odds Ratio's (OR) of each score having a low Se were calculated. The test characteristics (i.e., sensitivity, specificity) were calculated in order to provide insights on the performance of the risk-model.

\subsubsection{Comparing Determinants and Prognosis of Low Se and ID}

In order to visualize the prevalence of ID in comparison to low Se with regard to the identified predictors, restricted cubic splines (five knots for all variables) were constructed. The prevalence of anemia was also assessed in these analyses as a reference. The influence of low Se and ID on the outcome was further assessed using a Cox proportional hazard regression analysis. Both low Se and ID were added together in the models to assess the independency and additionally corrected for the BIOSTAT-CHF risk-models that predict the 2-year combined endpoint of HF hospitalizations and mortality and the 2-year all-cause mortality alone [20]. 


\section{Results}

\subsection{Patient Characteristics}

The mean Se concentration in the studied cohort of $2328 \mathrm{HF}$ patients was $89.1(24.8) \mu \mathrm{g} / \mathrm{mL}$, with $1633(70.1 \%)$ of patients having Se values $<100 \mu \mathrm{g} / \mathrm{L}$. The differences between patients with a low Se and a normal Se were largely similar to those previously reported for patients with a Se deficiency $(<70 \mu \mathrm{g} / \mathrm{L})$ [15]. Patients with a low Se were significantly older (70.1 [ \pm 11.9$]$ years vs. $66.0[ \pm 11.8]$, $p<0.001)$, were more likely to be female $(28.0 \%$ vs. $21.6 \%, p<0.001)$, had worse symptoms $(39.6 \%$ NYHA class III/IV vs. $30.1 \%, p<0.001)$, were more likely to have a left ventricular ejection fraction $>40 \%(21.3 \%$ vs. $12.9 \%, p<0.001)$, and had a higher prevalence of renal insufficiency (estimated Glomerular Filtration Rate (eGFR) $<60 \mathrm{~mL} / \mathrm{min})(48.0 \%$ vs. 41.4\%, $p<0.001)$. Furthermore, low Se was associated with a pro-inflammatory profile (median IL6; 5.8 [3.2-11.4] vs. 3.9 [2.1-7.4] $\mu \mathrm{g} / \mathrm{L}, p<0.001$ ) and median C-reactive protein (CRP) (14,151.5 [6760.5-27,734.3] vs. 11,091.9 [4127.5-22,689.7] mg/L, $p<0.001)$, as well as higher cardiac biomarkers. In addition, ID was present in $1436(62.0 \%)$ patients, while anemia was present in $772(36.3 \%)$ patients (Table A2). The prevalence of both ID (66.4\% vs. $51.7 \%, p<0.001)$ and anemia $(39.2 \%$ vs. $28.9 \%, p<0.001)$ was higher in patients with low Se.

\subsection{The Clinical Predictors and Diagnostic Accuracy of the Risk-Model}

Older age, lower serum albumin, higher NT-proBNP levels, worse kidney function, and the presence of orthopnea and ID were independent predictors for low Se status (Table 1, c-statistic 0.6923). These determinants remained highly selective in the additional sensitivity analyses using bootstrapping and Lasso penalized regression (Tables A3 and A4). No multicollinearity was detected (variance inflation factors: 1.05-1.27). Although there were some variations between the selenium levels among the included countries, the geographical location did not remain statistically significant as a predictor in the stepwise multivariable logistic regression analysis (Table A5).

Table 1. Independent determinants of low selenium concentrations.

\begin{tabular}{ccccccc}
\hline Factor & Odds Ratio & Standard Error & $\mathbf{z}$ & $\boldsymbol{p}$ Value & 95\% Confidence Interval \\
\hline eGFR (Kidney Function) & 1.01 & 0.00 & 2.68 & 0.007 & 1.00 & 1.01 \\
Iron Deficiency & 1.36 & 0.14 & 3.02 & 0.002 & 1.11 & 1.66 \\
NTproBNP & 1.30 & 0.04 & 8.71 & $<0.001$ & 1.23 & 1.39 \\
Albumin & 0.97 & 0.01 & -4.55 & $<0.001$ & 0.96 & 0.99 \\
Orthopnoea & 1.43 & 0.15 & 3.31 & 0.001 & 1.16 & 1.77 \\
Age & 1.02 & 0.00 & 4.63 & $<0.001$ & 1.01 & 1.03 \\
\hline
\end{tabular}

Unsupervised discretization resulted in clusters with different densities per group (Table A6). NT-proBNP values $\geq 3900 \mathrm{ng} / \mathrm{L}$, an age of 81 years-old or older, albumin levels $\leq 24 \mathrm{~g} / \mathrm{L}$, or a kidney function $\leq 41 \mathrm{~mL} / \mathrm{min} / 1.73 \mathrm{~m}^{2}$ qualified patients to receive two points for each variable (Figure 1A). The percentage of patients with a low selenium concentration increases with higher scores, ranging from $43 \%$ of the total patients who scored 0 points to $100 \%$ who scored 10 points (Figure $1 \mathrm{~B}$ ). A score of $\geq 6$ points identified $>80 \%$ of patients with low selenium (sensitivity of $44 \%$, specificity of $80 \%$ ). A score $\geq 5$ leads to the most balanced statistical measures, with a sensitivity of $61 \%$ and specificity of $62 \%$, and only $1.26 \mathrm{HF}$ patients are needed to be tested to identify a case of low Se status (Table 2). In comparison, were all patients screened for low selenium concentrations, this would result in 1 positive case for every 2.4 patients. 


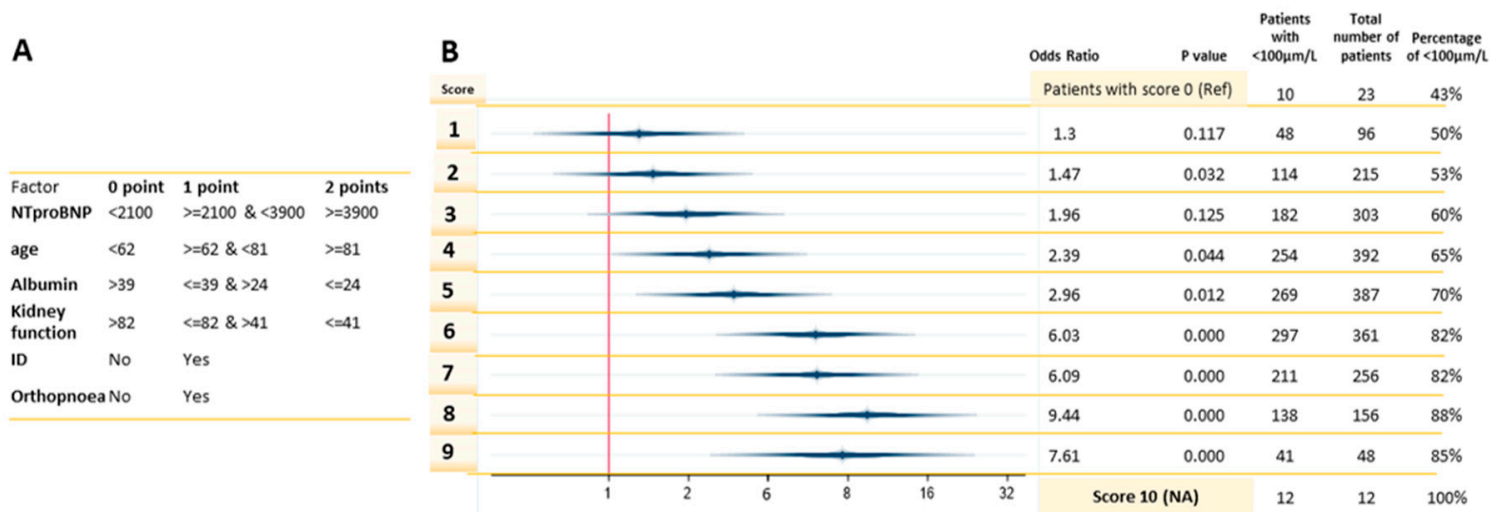

Figure 1. A risk-model using clinical variables to predict low Se. (A) Point distribution and cutoffs based on the unsupervised discretization. (B) Logistic regression of the risk-model with low selenium concentrations $(<100 \mu \mathrm{g} / \mathrm{L})$ as the outcome variable. Score 0 was the reference score.

Table 2. Statistical measures of all scores.

\begin{tabular}{ccccccc}
\hline Score & ROC $^{\#}$ & Sensitivity & Specificity & NPV $\ddagger$ & PPV $^{\dagger}$ & NNT * $^{*}$ \\
\hline 1 & 0.51 & $99 \%$ & $2 \%$ & 57 & 70 & 1.42 \\
2 & 0.53 & $96 \%$ & $9 \%$ & 51 & 71 & 1.40 \\
3 & 0.57 & $89 \%$ & $24 \%$ & 49 & 73 & 1.36 \\
4 & 0.60 & $77 \%$ & $42 \%$ & 44 & 76 & 1.32 \\
5 & 0.62 & $61 \%$ & $62 \%$ & 41 & 79 & 1.26 \\
6 & 0.62 & $44 \%$ & $80 \%$ & 38 & 84 & 1.19 \\
7 & 0.57 & $25 \%$ & $89 \%$ & 34 & 85 & 1.18 \\
8 & 0.54 & $12 \%$ & $96 \%$ & 32 & 88 & 1.14 \\
9 & 0.51 & $3 \%$ & $99 \%$ & 30 & 88 & 1.13 \\
10 & 0.50 & $1 \%$ & $100 \%$ & 30 & 100 & 1 \\
\hline
\end{tabular}

\# Receiver operating characteristic; ${ }^{\ddagger}$ Negative Predictive Value; ${ }^{\dagger}$ Positive Predictive Value; ${ }^{*}$ number needed to treat.

\subsection{Prevalence of Se, Iron, and Anemia in Association with the Identified Clinical Predictors}

Each predictor for low Se was associated significantly with ID and anemia in restricted cubic splines $(p<0.05)$. Patients aged $>65$ years and/or with an albumin $< \pm 32 \mathrm{~g} / \mathrm{L}$ had a higher risk of having any of these deficiencies (Figure 2A,B). Low Se and ID show similar associations with the NT-proBNP levels and eGFR. Anemia is especially strongly associated with renal function; a sharp increase in the prevalence of anemia can be observed at patients with an eGFR $<60 \mathrm{~mL} / \mathrm{min} / 1.73 \mathrm{~m}^{2}$ (Figure 2D). Restricted cubic splines were also constructed for the daily protein intake and CRP, as it was shown to be a risk factor for ID [9]. Low Se, ID, and anemia all show a similar increasing prevalence with a lower estimated protein intake (Figure 2E), while CRP was strongly associated with mainly ID (Figure 2F).

\subsection{Associations with Prognosis Comparing Low Serum Se Concentrations and ID}

Both low Se and ID were associated with an unfavorable prognosis univariably and were also independent from each other (Figure 3). In order to assess the associations of low Se and ID with a prognosis independent from each other and known cardiovascular risk factors, we analyzed both by adding them as factors in the previously established BIOSTAT models [20]. Both low Se and ID were significantly associated with the combined 2-year endpoint of HF hospitalizations and mortality (hazard ratio (HR) 1.23; 95\% confidence interval (CI) 1.05-1.44; $p=0.009$ and HR 1.26; 95\% CI 1.09-1.45; $p=0.002$, respectively). Low Se remained independently associated with 2-year all-cause mortality (HR 1.38; 95\% CI 1.13-1.69; $p=0.001$ ) when corrected for ID (Figure 3). 
A
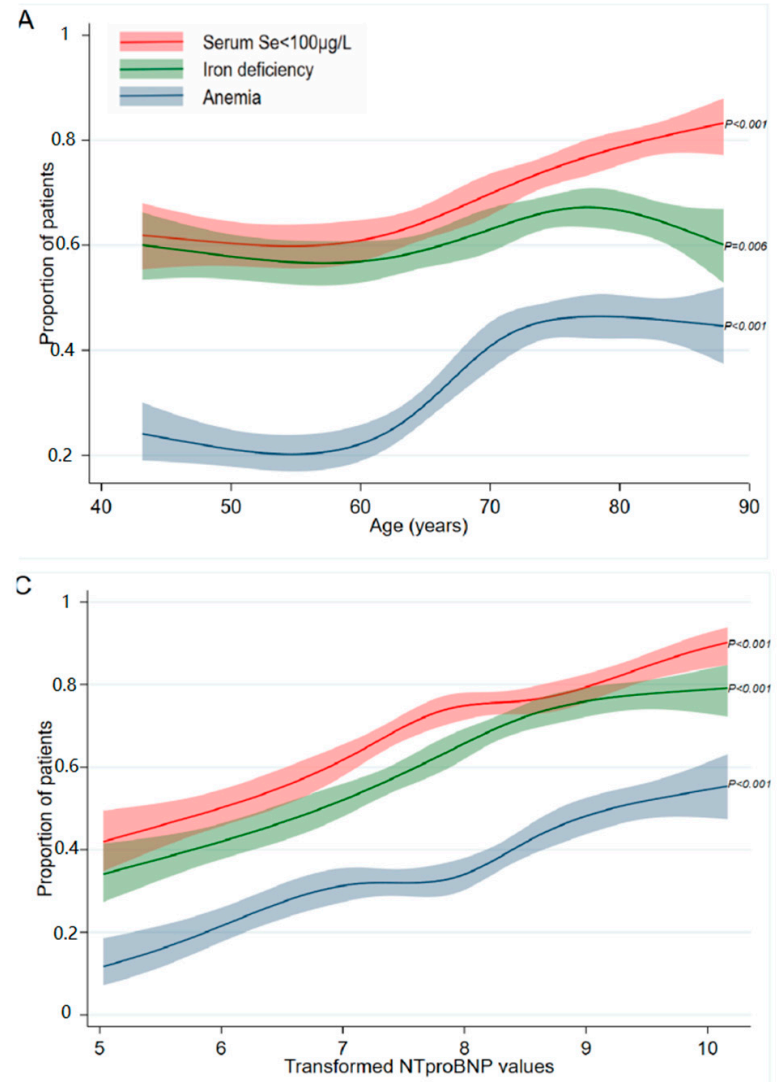

E

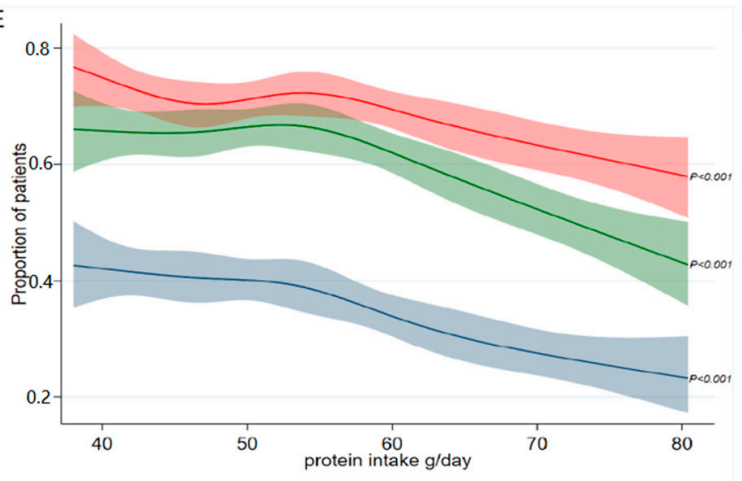

B

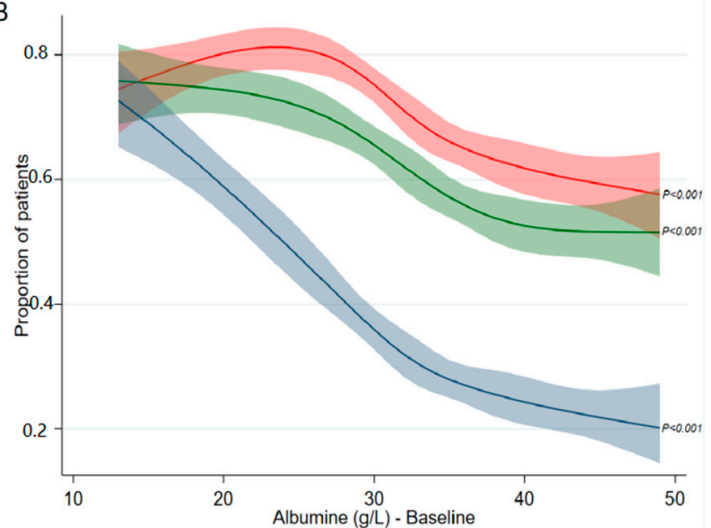

D

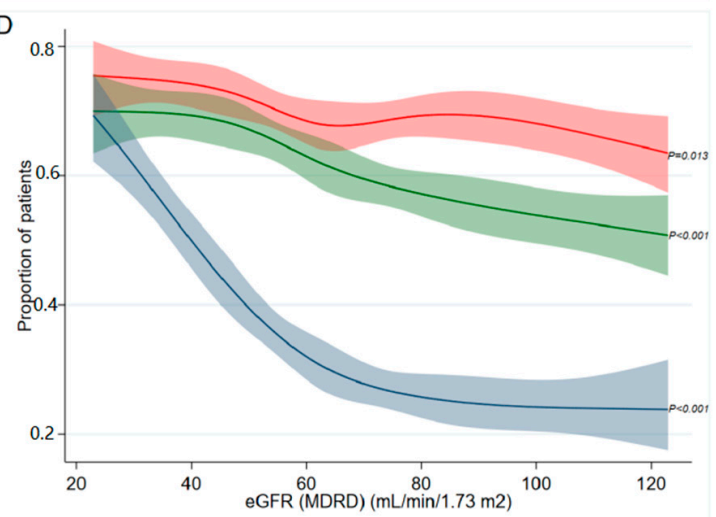

F

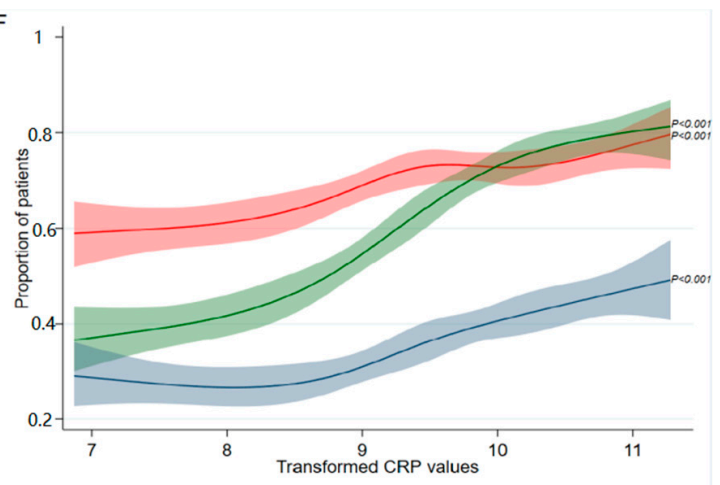

Figure 2. Comparing the prevalence of low serum Se concentrations, ID, and anemia. Restricted cubic splines of the association between the prevalence of serum selenium $<100 \mu \mathrm{g} / \mathrm{L}$, iron deficiency, and anemia and (A) age, (B) albumin levels, (C) transformed NT-proBNP values, (D) kidney function (according to the MDRD formula), (E) estimated protein intake, and (F) transformed CRP values. The solid lines indicate estimates of the prevalence of low selenium concentrations (red), ID (green), and anemia (blue) across continuous levels of the identified clinical determinants of low selenium, fitted using a logistic regression analysis. The shaded areas indicate $95 \%$ confidence intervals. The $p$-values indicate the significance of the whole cubic spline model for each factor. 


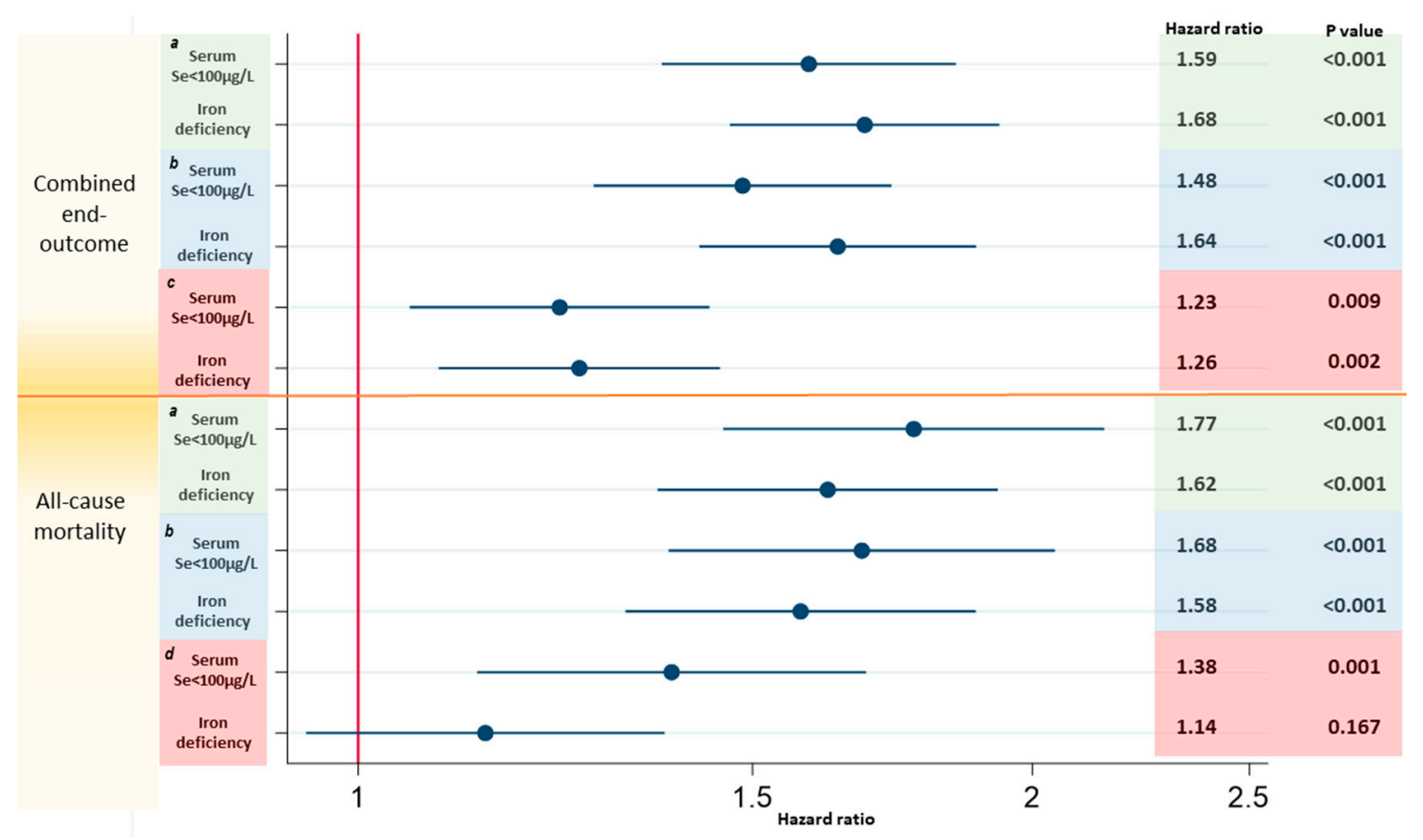

Figure 3. Comparing associations with prognosis for low serum Se concentrations and ID. Cox regression models for the prediction of the combined outcome and all-cause mortality. (a): serum selenium $<100 \mu \mathrm{g} / \mathrm{L}$ or iron deficiency as univariate predictors in different models. (b): serum selenium $<100 \mu \mathrm{g} / \mathrm{L}$ and iron deficiency together in one model. (c): serum selenium $<100 \mu \mathrm{g} / \mathrm{L}$ and iron deficiency together in one model and corrected for the BIOSTAT-CHF risk-model, consisting of age, Heart Failure hospitalization in the year before inclusion, the presence of edema, higher NTproBNP, lower systolic blood pressure, hemoglobin, high-density lipoprotein (HDL) levels, serum sodium concentration, and failure to prescribe a beta-blocker. (d): serum selenium $<100 \mu \mathrm{g} / \mathrm{L}$ and iron deficiency together in one model and corrected for the BIOSTAT-CHF mortality risk-model, consisting of age, higher blood urea nitrogen (BUN), NT-proBNP, hemoglobin, and failure to prescribe a beta-blocker.

\section{Discussion}

Using an established cohort of patients with worsening HF, we used independent predictors of low Se $(<100 \mu \mathrm{g} / \mathrm{L})$ —older age, lower levels of albumin, worse kidney function, higher levels of NT-proBNP, and the presence of orthopnea and ID—to establish a prediction tool for low selenium in HF patients. Low serum selenium concentrations were present in $1633(70.1 \%)$ HF patients. By taking a score of 6 or higher in this scoring system, the number of samples needed to be tested for one positive case could be reduced from 2.4 to 1.19. With the exception of CRP, the prevalence of low Se and ID showed similar patterns in relation to the clinical predictors. Additionally, a low Se was independent of ID, and the previously established risk factors were associated with the primary (combined) endpoint and mortality alone.

In contrast to what has been reported previously [24,25], smoking, alcohol, or BMI were not significantly associated with selenium status. Although subjects from most countries had similar selenium levels and geographical location was not independently associated with low selenium levels, relatively high selenium levels were found in subjects from Italy and low levels were seen in subjects from Slovenia (Table A5). Italy was the only country with mean selenium levels of above $100 \mu \mathrm{g} / \mathrm{L}$, which might be attributed to the Mediterranean diet, which contains selenium-rich components such as fish and nuts [26]. 


\subsection{Using Clinical Variables to Predict Low Se}

The developed a risk-model that could facilitate the efficient identification of patients at high risk of having a low Se level-for example, in the case of screening for a clinical trial targeting Se as an interventional therapy. With a score of 6 points or higher, approximately $80 \%$ of patients with a serum Se $<100 \mu \mathrm{g} / \mathrm{L}$ could be identified. We recently showed that serum Se levels between 70 and $100 \mu \mathrm{g} / \mathrm{L}$ appeared to have similar adverse associations such as deficiency $(<70 \mu \mathrm{g} / \mathrm{L})$, suggesting that values $<100 \mu \mathrm{g} / \mathrm{L}$ might be considered insufficient for the physiological requirement and thus abnormal $[27,28]$. This is supported by molecular evidence that shows that a serum Se of at least $100 \mu \mathrm{g} / \mathrm{L}$ is needed to have optimal glutathione peroxidase (GPx) and Selenoprotein P activity [29-33]. Determining the Se baseline concentrations is essential, as only those with suboptimal levels might benefit from supplementation, although such a hypothesis needs to be evaluated in a well-designed clinical trial. While the risk-model can help to detect approximately $84 \%$ of HF patients with low Se with a score $\geq 6$, it should be noted that ruling out low Se is challenging. Even in the population with a score of $0,43 \%$ of the patients had a low Se level.

\subsection{Clinical Predictors of Low Se}

\subsubsection{Age}

Age has been reported before as an important determinant of Se concentrations [25,34]. A decrease in the serum Se levels was mainly observed in patients older than 70 years. [25,35]. Decreased absorption capacity and impaired intestinal function with aging, as well as increased oxidative stress and inflammation in the elderly, are suggested as underlying causes [36,37]. Dietary intake also seems to play a relevant role, as those with a lower protein intake were more likely to have low Se status, although it was not an independent predictor of Se status (Figure 2E).

\subsubsection{NT-proBNP and Orthopnea}

In a placebo controlled intervention study, Se supplementation (in combination with coenzyme Q10) showed a reduction in the 10-year cardiovascular mortality and NT-proBNP levels in healthy elderly, supporting the hypothesis of a causal relationship between Se and NT-proBNP [38]. Orthopnea, a sign of congestive HF, represents the deteriorated cardiac health status.

\subsubsection{Kidney Function and Albumin}

Worse kidney function and lower Se status frequently occur simultaneously [39,40]. A recent in vivo study illustrated that a Se-deficient diet led to significant increase in the urinary protein/creatinine ratio, a reduction in the mitochondrial protein levels, increased oxidative stress markers, as well as histological changes in kidney tissues, suggesting a causative role of Se deficiency in inducing kidney injury [41].

Next to this, several observational patient studies showed a positive correlation between Se and albumin levels [42,43], which was substantiated by in vivo evidence showing that Se supplementation increased albumin concentration [44]. However, residual confounding or a reverse association (i.e., low albumin leads to low Se levels) cannot be excluded, as approximately $10 \%$ of the total serum Se binds to albumin [42].

\subsubsection{Iron Deficiency}

ID as a determinant for low serum Se concentrations has not been reported previously. However, several studies reported the presence of ID in Se-deficient patients [45,46]. Shared risk factors and dietary effects are likely to play a role, although the availability of Se in the diet is more geographically dependent on its concentration in the soil. While they are both mainly absorbed in the duodenum, it is not clear whether there is direct or indirect physiological interaction between both elements. 


\subsection{The Prevalence of Low Serum Se Concentrations, ID, and Anemia in Relation to the Determinants}

Our data show that low Se and ID have important similarities in their associations with patient characteristics. The similarity in the patterns supports the hypothesis that both elements share similar underlying detrimental processes. We previously reported that inflammation, chronic kidney disease, lower hemoglobin levels, and lower serum albumin levels were independent predictors for ID in HF patients [9].

\subsection{Low Serum Se Concentrations Associate with Worse Prognosis than ID}

Including both ID and low Se concentration in the BIOSTAT prediction models indicated that low Se status is independently associated with mortality in HF patients when additionally corrected for ID (Figure 3). Clinical trials of intravenous iron supplements have shown improvements in the symptoms and well-being of HF patients, and trials investigating the effects on morbidity and mortality are underway. Unlike iron, selenium is readily absorbed orally. However, it should be acknowledged that, although we showed that low Se was associated with a similar or worse prognosis compared to ID, more evidence from well-designed clinical trials, like those performed for ID, is needed to evaluate the potential benefits for Se supplementation in HF.

\subsection{Strengths and Limitations}

The BIOSTAT-CHF cohort is a large HF cohort in which comprehensive clinical and biochemical markers were measured. Nevertheless, it should be acknowledged that it included mainly patients with Caucasian origins. The development of a clinical tool to predict Se levels using clinical factors remains as a challenging task, as the sensitivity of having a score 6 in our model is $44 \%$. This could be attributed to the high prevalence of low Se levels in this cohort, and this may indicate that determining the Se status in patients with HF may be standardized when the clinical benefits are established in clinical trials. Additionally, due to the observational nature of the study, establishing a causal relationship between our results and Se concentrations is not possible. No data were currently available on other markers of selenium-dependent pathways, nor oxidative stress. As a result, other signaling components such as Selenoprotein P or gluthatione peroxidases were not investigated next to the serum selenium.

\section{Conclusions}

In this study, we developed a prediction tool which identifies HF patients at higher risk of having a low Se level. Yet, it remains a challenge to exclude patients with low Se levels based on clinical characteristics alone. Low Se and ID share to large extent similar predictors. Finally, a lower Se status is associated with similar or worse prognosis compared to, and independent of, ID.

Author Contributions: Conceptualization, N.G.B., N.B., and P.v.d.M.; methodology, A.A.A.-M., N.G.B., N.B.; formal analysis, A.A.A.-M., N.G.B., N.B.; resources, S.D.A., N.J.S., K.D., G.F., D.J.v.V., A.A.V.; writing-original draft preparation, A.A.A.-M., N.G.B., N.B., P.v.d.M.; writing-review and editing, A.A.A.-M., N.G.B., A.A.V., N.B., P.v.d.M.; supervision, N.G.B., N.B., P.v.d.M.; funding acquisition, A.A.V. All the authors have read and agreed to the published version of the manuscript.

Funding: BIOSTAT-CHF was funded by a grant from the European Commission (FP7-242209-BIOSTAT-CHF). The funders had no role in the study design, data collection and analysis, decision to publish, or preparation of the manuscript.

Acknowledgments: The excellent technical assistance of Martin Dokter is gratefully acknowledged.

Conflicts of Interest: The authors declare no conflict of interest. 


\section{Abbreviations}

HF, heart failure; CI, confidence interval; CRP, C-reactive protein; GPx, glutathione peroxidase; HFrEF, heart failure with reduced ejection fraction; HR, hazard ratio; ID, iron deficiency; LVEF, left ventricle ejection fraction; MDRD, modification of diet in renal disease; NT-proBNP, N-terminal pro-B-type natriuretic peptide; OR, odds ratio; Se, selenium; TSAT, transferrin saturation; eGFR, estimated Glomerular Filtration Rate.

\section{Appendix A}

Table A1. Selected variables that entered the analysis and their degree of missingness.

\begin{tabular}{ccc}
\hline Factor & & Percentage \\
\hline Age (years) & 0 & 0.00 \\
Females (\%) & 0 & 0.00 \\
Estimated protein intake (g/day) & 167 & 7.17 \\
NYHA functional class & 288 & 12.37 \\
Orthopnoea & 5 & 0.21 \\
Iron deficiency & 13 & 0.55 \\
Atrial fibrillation & 0 & 0.00 \\
CRP (mg/L) & 98 & 4.21 \\
NTproBNP (ng/L) & 58 & 2.49 \\
Albumine (g/L) & 7 & 0.30 \\
Hemoglobin & 12 & 0.52 \\
BGFR (MDR (m) & 200 & 8.59 \\
Aldosteron antagonist & 0 & 0.00 \\
Country & 0 & 0.00 \\
Heart rate (b.p.m) & 0 & 0.00 \\
& 6 & 0.99 \\
\hline
\end{tabular}

Table A2. Baseline characteristics.

\begin{tabular}{|c|c|c|c|c|c|}
\hline Factor & Level & Value & $\mathrm{Se} \geq 100 \mu \mathrm{g} / \mathrm{L}$ & $\mathrm{Se}<100 \mu \mathrm{g} / \mathrm{L}$ & $p$-Value \\
\hline $\mathrm{N}$ & & 2328 & 695 & 1633 & \\
\hline Selenium ( $\mu \mathrm{g} / \mathrm{L})$ & & $89.1(24.8)$ & $118.5(18.2)$ & $76.6(14.5)$ & $<0.001$ \\
\hline \multicolumn{6}{|l|}{ Demographics } \\
\hline Age (years) & & $68.8(12.0)$ & $66.0(11.8)$ & $70.1(11.9)$ & $<0.001$ \\
\hline Females (\%) & & $607(26.1 \%)$ & $150(21.6 \%)$ & $457(28.0 \%)$ & 0.001 \\
\hline BMI $(\mathrm{kg} / \mathrm{m} 2)$ & & $27.2(24.1,30.6)$ & $27.7(24.4,30.7)$ & $26.9(24.0,30.6)$ & 0.072 \\
\hline Estimated protein intake (g/day) & & $53.4(46.5,62.0)$ & $54.6(47.3,64.6)$ & $52.9(46.1,61.1)$ & $<0.001$ \\
\hline Ischemic etiology & & $1057(46.2 \%)$ & $315(46.2 \%)$ & $742(46.2 \%)$ & 0.98 \\
\hline $\operatorname{LVEF}(\%)$ & & $30.0(25.0,36.0)$ & $30.0(25.0,35.0)$ & $30.0(25.0,38.0)$ & 0.002 \\
\hline HFrEF (LVEF < 40) & & $1691(81.3 \%)$ & $554(87.1 \%)$ & $1137(78.7 \%)$ & $<0.001$ \\
\hline \multirow[t]{4}{*}{ NYHA functional class } & Class I & $214(10.5 \%)$ & $83(13.3 \%)$ & $131(9.3 \%)$ & $<0.001$ \\
\hline & Class II & $1077(52.8 \%)$ & $353(56.6 \%)$ & $724(51.1 \%)$ & \\
\hline & Class III & $672(32.9 \%)$ & $174(27.9 \%)$ & $498(35.2 \%)$ & \\
\hline & Class IV & $77(3.8 \%)$ & $14(2.2 \%)$ & $63(4.4 \%)$ & \\
\hline Previous hospitalization for HF & & $720(30.9 \%)$ & $201(28.9 \%)$ & $519(31.8 \%)$ & 0.17 \\
\hline Heart rate (b.p.m) & & $76.0(66.0,90.0)$ & $75.0(65.0,86.0)$ & $77.0(68.0,90.0)$ & $<0.001$ \\
\hline Systolic blood pressure (mmHg) & & $120.0(110.0,138.0)$ & $120.0(110.0,135.0)$ & $120.0(110.0,140.0)$ & 0.39 \\
\hline Diastolic blood pressure $(\mathrm{mmHg})$ & & $74.9(13.1)$ & $75.0(12.3)$ & $74.8(13.5)$ & 0.71 \\
\hline Peripheral oedema & & $1149(59.4 \%)$ & $255(44.6 \%)$ & $894(65.6 \%)$ & $<0.001$ \\
\hline Pulmonary oedema & & $507(32.2 \%)$ & $128(30.7 \%)$ & $379(32.8 \%)$ & 0.44 \\
\hline \multirow[t]{3}{*}{ Elevated JVP } & No & $1025(62.9 \%)$ & $393(75.9 \%)$ & $632(56.8 \%)$ & $<0.001$ \\
\hline & Yes & $514(31.5 \%)$ & $102(19.7 \%)$ & $412(37.1 \%)$ & \\
\hline & Uncertain & $91(5.6 \%)$ & $23(4.4 \%)$ & $68(6.1 \%)$ & \\
\hline Orthopnoea & & $802(34.5 \%)$ & $180(25.9 \%)$ & $622(38.2 \%)$ & $<0.001$ \\
\hline Hepatomegaly & & $331(14.3 \%)$ & $102(14.7 \%)$ & $229(14.1 \%)$ & 0.71 \\
\hline Completion of $6 \mathrm{MWT}$ & & $1462(64.9 \%)$ & $499(73.4 \%)$ & $963(61.2 \%)$ & $<0.001$ \\
\hline Result 6MWT (m) & & $330.0(180.0,429.0)$ & $365.5(240.0,449.0)$ & $310.0(143.0,420.0)$ & $<0.001$ \\
\hline KCCQ (overall score) & & $49.0(31.3,66.7)$ & $56.3(38.5,71.9)$ & $44.8(29.2,63.5)$ & $<0.001$ \\
\hline \multirow[t]{3}{*}{ Smoking (none, past, current) } & None & $853(36.7 \%)$ & $235(33.9 \%)$ & $618(37.9 \%)$ & 0.18 \\
\hline & Past & $1138(48.9 \%)$ & $354(51.0 \%)$ & $784(48.1 \%)$ & \\
\hline & Current & $334(14.4 \%)$ & $105(15.1 \%)$ & $229(14.0 \%)$ & \\
\hline Current alcohol use & & $644(27.7 \%)$ & $196(28.3 \%)$ & $448(27.5 \%)$ & 0.69 \\
\hline
\end{tabular}


Table A2. Cont.

\begin{tabular}{|c|c|c|c|c|c|}
\hline Factor & Level & Value & $\mathrm{Se} \geq 100 \mu \mathrm{g} / \mathrm{L}$ & $\mathrm{Se}<100 \mu \mathrm{g} / \mathrm{L}$ & $p$-Value \\
\hline \multicolumn{6}{|l|}{ Medical history } \\
\hline Myocardial infarction & & $891(38.3 \%)$ & $258(37.1 \%)$ & $633(38.8 \%)$ & 0.46 \\
\hline CABG & & $402(17.3 \%)$ & $133(19.1 \%)$ & $269(16.5 \%)$ & 0.12 \\
\hline Valvular surgery & & $171(7.3 \%)$ & $54(7.8 \%)$ & $117(7.2 \%)$ & 0.61 \\
\hline PCI & & $512(22.0 \%)$ & $162(23.3 \%)$ & $350(21.4 \%)$ & 0.32 \\
\hline Atrial fibrillation & & $1048(45.0 \%)$ & $272(39.1 \%)$ & $776(47.5 \%)$ & $<0.001$ \\
\hline Device therapy & & $580(24.9 \%)$ & $190(27.3 \%)$ & $390(23.9 \%)$ & 0.078 \\
\hline Stroke & & $214(9.2 \%)$ & $53(7.6 \%)$ & $161(9.9 \%)$ & 0.088 \\
\hline Peripheral arterial disease & & $251(10.8 \%)$ & $75(10.8 \%)$ & $176(10.8 \%)$ & 0.99 \\
\hline $\begin{array}{c}\text { Renal insufficiency (eGFR }<60 \\
\mathrm{~mL} / \mathrm{min})\end{array}$ & & $1068(46.0 \%)$ & 287 (41.4\%) & $781(48.0 \%)$ & 0.003 \\
\hline Renal disease (history) & & $646(27.7 \%)$ & $167(24.0 \%)$ & $479(29.3 \%)$ & 0.009 \\
\hline Hypertension & & $1452(62.4 \%)$ & $428(61.6 \%)$ & $1024(62.7 \%)$ & 0.61 \\
\hline Diabetes mellitus & & $750(32.2 \%)$ & $222(31.9 \%)$ & $528(32.3 \%)$ & 0.85 \\
\hline COPD & & $403(17.3 \%)$ & $109(15.7 \%)$ & $294(18.0 \%)$ & 0.18 \\
\hline \multicolumn{6}{|l|}{ Laboratory } \\
\hline $\mathrm{CRP}(\mathrm{mg} / \mathrm{L})$ & & $\begin{array}{c}13,142.2(5818.3 \\
26416.6)\end{array}$ & $\begin{array}{c}11,091.9(4127.5 \\
22689.7)\end{array}$ & $\begin{array}{c}14,151.5(6760.5 \\
27734.3)\end{array}$ & $<0.001$ \\
\hline Creatinin $(\mu \mathrm{mol} / \mathrm{L})$ & & $101.0(82.2,129.0)$ & $100.0(82.1,123.8)$ & $101.4(82.2,131.6)$ & 0.24 \\
\hline Urea $(\mathrm{mmol} / \mathrm{L})$ & & $11.3(7.6,18.2)$ & $12.1(7.8,19.2)$ & $11.0(7.5,17.8)$ & 0.049 \\
\hline Proteinuria (mg/dL) & & $5.0(0.0,20.0)$ & $5.0(0.0,20.0)$ & $2.0(0.0,20.0)$ & 0.68 \\
\hline Sodium (mmol/L) & & $139.2(3.9)$ & $139.4(3.5)$ & $139.1(4.1)$ & 0.25 \\
\hline Potassium (mmol/L) & & $4.3(0.6)$ & $4.3(0.5)$ & $4.3(0.6)$ & 0.95 \\
\hline NTproBNP (ng/L) & & $\begin{array}{l}2698.0(1179.0 \\
5751.0)\end{array}$ & $\begin{array}{l}1628.5(696.5 \\
3791.0)\end{array}$ & $\begin{array}{l}3224.0(1483.0 \\
\quad 6635.5)\end{array}$ & $<0.001$ \\
\hline GDF15, median (IQR) & & $\begin{array}{l}2720.0(1712.0 \\
4556.0)\end{array}$ & $\begin{array}{l}2133.0(1346.0 \\
3577.0)\end{array}$ & $\begin{array}{l}3021.5(1915.5 \\
5224.5)\end{array}$ & $<0.001$ \\
\hline eGFR (MDRD) (mL/min/1.73 m2) & & $65.0(26.3)$ & $67.7(27.5)$ & $63.9(25.7)$ & 0.001 \\
\hline IL-6 $(\mathrm{pg} / \mathrm{mL})$ & & $5.2(2.8,10.2)$ & $3.9(2.1,7.4)$ & $5.8(3.2,11.4)$ & $<0.001$ \\
\hline Total bilirubin $(\mu \mathrm{mol} / \mathrm{L})$ & & $14.0(9.9,21.0)$ & $13.2(9.1,18.8)$ & $14.3(10.0,22.2)$ & 0.001 \\
\hline Leucocytes (10e9/L) & & $8.3(2.9)$ & $8.3(2.7)$ & $8.3(2.9)$ & 0.95 \\
\hline Troponin I $(\mu \mathrm{g} / \mathrm{L})$ & & $0.0(0.0,0.1)$ & $0.0(0.0,0.1)$ & $0.0(0.0,0.1)$ & 0.006 \\
\hline Troponin T $(\mu \mathrm{g} / \mathrm{L})$ & & $0.0(0.0,0.1)$ & $0.0(0.0,0.1)$ & $0.0(0.0,0.1)$ & 0.71 \\
\hline Glucose (mmol/L) & & $6.3(5.4,7.9)$ & $6.3(5.4,8.0)$ & $6.2(5.3,7.9)$ & 0.22 \\
\hline HbA1c (\%) & & $6.3(5.7,7.1)$ & $6.4(5.8,7.3)$ & $6.2(5.7,7.0)$ & 0.24 \\
\hline ASAT (U/L) & & $25.4(19.0,35.0)$ & $25.0(19.0,35.0)$ & $26.0(20.0,35.0)$ & 0.35 \\
\hline ALAT (U/L) & & $25.0(17.0,38.0)$ & $28.0(20.0,42.0)$ & $23.0(16.0,36.0)$ & $<0.001$ \\
\hline$\gamma-\mathrm{GT}(\mathrm{U} / \mathrm{L})$ & & $55.0(28.0,108.5)$ & $44.0(26.0,84.0)$ & $60.0(29.0,118.0)$ & $<0.001$ \\
\hline Alkaline phosphatase $(\mu \mathrm{g} / \mathrm{L})$ & & $84.0(65.0,118.0)$ & $77.0(62.0,104.0)$ & $88.0(67.0,122.0)$ & $<0.001$ \\
\hline HDL $(\mathrm{mmol} / \mathrm{L})$ & & $1.1(0.8,1.3)$ & $1.1(0.9,1.3)$ & $1.0(0.8,1.3)$ & 0.065 \\
\hline $\mathrm{LDL}(\mathrm{mmol} / \mathrm{L})$ & & $2.6(1.1)$ & $2.8(1.1)$ & $2.5(1.1)$ & $<0.001$ \\
\hline Total cholesterol (mmol/L) & & $4.3(1.3)$ & $4.5(1.4)$ & $4.2(1.3)$ & $<0.001$ \\
\hline Triglycerides (mmol/L) & & $1.2(0.9,1.7)$ & $1.3(1.0,1.8)$ & $1.2(0.9,1.6)$ & $<0.001$ \\
\hline $\mathrm{TSH}(\mathrm{mU} / \mathrm{L})$ & & $1.8(1.2,3.0)$ & $1.8(1.1,3.2)$ & $1.8(1.2,3.0)$ & 0.85 \\
\hline FT4 (pmol/L) & & $16.8(7.6)$ & $17.3(10.6)$ & $16.5(5.6)$ & 0.29 \\
\hline Albumine (g/L) & & $33.0(27.0,38.0)$ & $34.0(30.0,40.0)$ & $32.0(26.5,37.0)$ & $<0.001$ \\
\hline Hemoglobin (g/dL) & & $13.2(1.9)$ & $13.6(1.8)$ & $13.0(1.9)$ & $<0.001$ \\
\hline Anemia & & $772(36.3 \%)$ & $176(28.9 \%)$ & $596(39.2 \%)$ & $<0.001$ \\
\hline Mean corpuscular volume (fL) & & $90.4(8.6)$ & $91.0(7.8)$ & $90.2(8.9)$ & 0.097 \\
\hline Iron deficiency & & $1436(62.0 \%)$ & $357(51.7 \%)$ & $1079(66.4 \%)$ & $<0.001$ \\
\hline Iron $(\mathrm{mg} / \mathrm{dL})$ & & $44.7(27.9,72.6)$ & $55.9(39.1,78.2)$ & $44.7(27.9,67.0)$ & $<0.001$ \\
\hline Ferritin $(\mu \mathrm{g} / \mathrm{L})$ & & $101.0(50.0,191.5)$ & $126.0(62.5,208.0)$ & $93.0(46.0,185.0)$ & $<0.001$ \\
\hline Transferrin $(\mathrm{mg} / \mathrm{dL})$ & & $206.0(69.7)$ & $211.9(67.9)$ & $203.5(70.4)$ & 0.008 \\
\hline Transferrin saturation (\%) & & $17.1(10.9,24.9)$ & $19.9(13.3,27.2)$ & $15.9(9.9,23.5)$ & $<0.001$ \\
\hline Hepcidin (nmol/L) & & $6.3(2.2,16.5)$ & $7.5(3.1,17.3)$ & $5.7(1.8,15.9)$ & $<0.001$ \\
\hline sTfR (mg/L) & & $1.8(1.0)$ & $1.5(0.8)$ & $1.9(1.1)$ & $<0.001$ \\
\hline \multicolumn{6}{|l|}{ Medication } \\
\hline Betablocker - baseline & & $1941(83.4 \%)$ & $597(85.9 \%)$ & $1344(82.3 \%)$ & 0.033 \\
\hline ACE/ARB - baseline & & $1685(72.4 \%)$ & $522(75.1 \%)$ & $1163(71.2 \%)$ & 0.055 \\
\hline Antiplatelets & & $1208(51.9 \%)$ & $363(52.2 \%)$ & $845(51.7 \%)$ & 0.83 \\
\hline P2Y12V2 & & $359(15.4 \%)$ & $101(14.5 \%)$ & $258(15.8 \%)$ & 0.44 \\
\hline Diuretics & & $2326(99.9 \%)$ & $694(99.9 \%)$ & $1632(99.9 \%)$ & 0.53 \\
\hline Loop Diuretics & & $2317(99.5 \%)$ & $690(99.3 \%)$ & $1627(99.6 \%)$ & 0.26 \\
\hline Oral anti-diabetics & & $469(62.5 \%)$ & $133(59.9 \%)$ & $336(63.6 \%)$ & 0.34 \\
\hline Insuline use & & $301(40.1 \%)$ & $93(41.9 \%)$ & $208(39.4 \%)$ & 0.52 \\
\hline Proton pump inhibitor & & $815(35.0 \%)$ & $237(34.1 \%)$ & $578(35.4 \%)$ & 0.55 \\
\hline Acenocoumarol & & $896(38.5 \%)$ & $258(37.1 \%)$ & $638(39.1 \%)$ & 0.38 \\
\hline Aldosteron antagonist & & $1241(53.3 \%)$ & $398(57.3 \%)$ & $843(51.6 \%)$ & 0.013 \\
\hline Spironolactone & & $855(36.7 \%)$ & $250(36.0 \%)$ & $605(37.0 \%)$ & 0.62 \\
\hline
\end{tabular}

LVEF, Left Ventricular Ejection Fraction; HF, Heart Failure; JVP, Jugular Venous Pressure; CABG, Coronary Artery Bypass Grafting; PCI, Percutaneous coronary intervention; COPD, Chronic Obstructive Pulmanory Disease. 
Table A3. Results of the bootstrapping analysis.

\begin{tabular}{cc}
\hline & N. of Repetion \\
\hline Age (years) & 856 \\
NTproBNP (per doubling) & 1000 \\
eGFR (MDRD) (mL/min/1.73 m2) & 838 \\
Albumine (g/L) & 859 \\
Iron deficiency & 553 \\
Orthopnoea & 813 \\
\hline
\end{tabular}

Table A4. Results of LASSO penalized regression.

\begin{tabular}{cc}
\hline Predictor $^{\#}$ & Penalized Odds Ratios \\
\hline NTproBNP & 1.32 \\
Albumin & 0.98 \\
Kidney function (eGFR MDRD) & 1.01 \\
Age & 1.01 \\
Iron deficiency & 1.23 \\
Orthopnoea & 1.38 \\
\hline
\end{tabular}

\# Variables are ordered based on their absolute values of their coefficients, starting from the largest. LASSO, Least Absolute Shrinkage and Selection Operator.

Table A5. Selenium values based on geographical location.

\begin{tabular}{cccc}
\hline Country & $\begin{array}{c}\text { Number of Included } \\
\text { Patients }\end{array}$ & Mean Selenium & $\begin{array}{c}\text { Percentage of } \\
\text { Patients }<\mathbf{1 0 0} \boldsymbol{\mu g} / \mathbf{L}\end{array}$ \\
\hline the Netherlands & 386 & 86.00 & 76.68 \\
France & 243 & 80.70 & 80.66 \\
Germancy & 87 & 90.69 & 67.82 \\
Serbia & 382 & 91.23 & 66.49 \\
Slovenia & 43 & 66.83 & 97.67 \\
Greece & 285 & 90.87 & 68.42 \\
Italy & 297 & 115.48 & 27.61 \\
Norway & 108 & 79.16 & 86.11 \\
Sweden & 97 & 79.49 & 84.54 \\
Poland & 239 & 79.33 & 87.45 \\
United Kingdom & 161 & 84.42 & 77.64 \\
\hline
\end{tabular}

Table A6. Number of patients with selenium $<100 \mu \mathrm{g} / \mathrm{L}$ per cluster per variable.

\begin{tabular}{ccccc}
\hline Factor & 0 Point & 1 Point & 2 Points & Total Number of Patients \\
\hline NTproBNP & 555 & 352 & 685 & 1592 \\
eGFR Kidney Function & 343 & 977 & 307 & 1627 \\
Albumin & 264 & 1050 & 310 & 1624 \\
Age & 374 & 972 & 287 & 1633 \\
Iron deficiency & 545 & 1079 & NA & 1624 \\
Orthopnoea & 1006 & 622 & NA & 1628 \\
\hline
\end{tabular}

\section{References}

1. Ponikowski, P.; Voors, A.A.; Anker, S.D.; Bueno, H.; Cleland, J.G.F.; Coats, A.J.S.; Falk, V.; González-Juanatey, J.R.; Harjola, V.-P.; Jankowska, E.A.; et al. 2016 ESC Guidelines for the diagnosis and treatment of acute and chronic heart failure: The Task Force for the diagnosis and treatment of acute and chronic heart failure of the European Society of Cardiology (ESC). Developed with the special contribution. Eur. J. Heart Fail. 2016, 18, 891-975. [CrossRef] [PubMed]

2. Cascino, T.M.; Hummel, S.L. Nutrient deficiencies in heart failure: A micro problem with macro effects? J. Am. Heart Assoc. 2018, 7, 1-3. [CrossRef] [PubMed] 
3. Loscalzo, J. Keshan Disease, Selenium Deficiency, and the Selenoproteome. N. Engl. J. Med. 2014, 370, 1756-1760. [CrossRef] [PubMed]

4. Yoshihisa, A.; Abe, S.; Kiko, T.; Kimishima, Y.; Sato, Y.; Watanabe, S.; Kanno, Y.; Miyata-Tatsumi, M.; Misaka, T.; Sato, T.; et al. Association of Serum Zinc Level with Prognosis in Patients With Heart Failure. J. Card. Fail. 2018, 24, 375-383. [CrossRef] [PubMed]

5. McKeag, N.A.; McKinley, M.C.; Harbinson, M.T.; McGinty, A.; Neville, C.E.; Woodside, J.V.; McKeown, P.P. Dietary Micronutrient Intake and Micronutrient Status in Patients With Chronic Stable Heart Failure. J. Cardiovasc. Nurs. 2017, 32, 148-155. [CrossRef] [PubMed]

6. Lennie, T.A.; Andreae, C.; Rayens, M.K.; Song, E.K.; Dunbar, S.B.; Pressler, S.J.; Heo, S.; Kim, J.S.; Moser, D.K. Micronutrient deficiency independently predicts time to event in patients with heart failure. J. Am. Heart Assoc. 2018, 7, 1-10. [CrossRef]

7. Grote Beverborg, N.; Van Der Wal, H.H.; Klip, I.T.; Anker, S.D.; Cleland, J.; Dickstein, K.; Van Veldhuisen, D.J.; Voors, A.A.; Van Der Meer, P. Differences in Clinical Profile and Outcomes of Low Iron Storage vs Defective Iron Utilization in Patients with Heart Failure: Results from the DEFINE-HF and BIOSTAT-CHF Studies. JAMA Cardiol. 2019, 4, 696-701. [CrossRef]

8. Hoes, M.F.; Grote Beverborg, N.; Kijlstra, J.D.; Kuipers, J.; Swinkels, D.W.; Giepmans, B.N.G.; Rodenburg, R.J.; van Veldhuisen, D.J.; de Boer, R.A.; van der Meer, P. Iron deficiency impairs contractility of human cardiomyocytes through decreased mitochondrial function. Eur. J. Heart Fail. 2018, 20, 910-919. [CrossRef]

9. van der Wal, H.H.; Grote Beverborg, N.; Dickstein, K.; Anker, S.D.; Lang, C.C.; Ng, L.L.; van Veldhuisen, D.J.; Voors, A.A.; van der Meer, P. Iron deficiency in worsening heart failure is associated with reduced estimated protein intake, fluid retention, inflammation, and antiplatelet use. Eur. Heart J. 2019, 40, 3616-3625. [CrossRef]

10. Anker, S.D.; Comin Colet, J.; Filippatos, G.; Willenheimer, R.; Dickstein, K.; Drexler, H.; Lüscher, T.F.; Bart, B.; Banasiak, W.; Niegowska, J.; et al. Ferric Carboxymaltose in Patients with Heart Failure and Iron Deficiency. N. Engl. J. Med. 2009, 361, 2436-2448. [CrossRef]

11. Van Veldhuisen, D.J.; Ponikowski, P.; Van Der Meer, P.; Metra, M.; Böhm, M.; Doletsky, A.; Voors, A.A.; MacDougall, I.C.; Anker, S.D.; Roubert, B.; et al. Effect of Ferric Carboxymaltose on Exercise Capacity in Patients With Chronic Heart Failure and Iron Deficiency. Circulation 2017, 136, 1374-1383. [CrossRef] [PubMed]

12. Ponikowski, P.; van Veldhuisen, D.J.; Comin-Colet, J.; Ertl, G.; Komajda, M.; Mareev, V.; McDonagh, T.; Parkhomenko, A.; Tavazzi, L.; Levesque, V.; et al. Beneficial effects of long-term intravenous iron therapy with ferric carboxymaltose in patients with symptomatic heart failure and iron deficiencyt. Eur. Heart J. 2014, 36, 657-668. [CrossRef] [PubMed]

13. Ponikowski, P.; Kirwan, B.-A.; Anker, S.D.; Dorobantu, M.; Drozdz, J.; Fabien, V.; Filippatos, G.; Haboubi, T.; Keren, A.; Khintibidze, I.; et al. Rationale and design of the AFFIRM-AHF trial: A randomised, double-blind, placebo-controlled trial comparing the effect of intravenous ferric carboxymaltose on hospitalisations and mortality in iron-deficient patients admitted for acute heart failure. Eur. J. Heart Fail. 2019, 21, 1651-1658. [CrossRef] [PubMed]

14. Zhou, H.; Wang, T.; Li, Q.; Li, D. Prevention of Keshan Disease by Selenium Supplementation: A Systematic Review and Meta-analysis. Biol. Trace Elem. Res. 2018, 186, 98-105. [CrossRef] [PubMed]

15. Bomer, N.; Grote Beverborg, N.; Hoes, M.F.; Streng, K.W.; Vermeer, M.; Dokter, M.M.; IJmker, J.; Anker, S.D.; Cleland, J.G.F.; Hillege, H.L.; et al. Selenium and outcome in heart failure. Eur. J. Heart Fail. 2019, 1-9. [CrossRef]

16. Spertus, J.; Peterson, E.; Conard, M.W.; Heidenreich, P.A.; Krumholz, H.M.; Jones, P.; McCullough, P.A.; Pina, I.; Tooley, J.; Weintraub, W.S.; et al. Monitoring clinical changes in patients with heart failure: A comparison of methods. Am. Heart J. 2005, 150, 707-715. [CrossRef]

17. Spertus, J.A.; Jones, P.G. Development and Validation of a Short Version of the Kansas City Cardiomyopathy Questionnaire. Circ. Cardiovasc. Qual. Outcomes 2015, 8, 469-476. [CrossRef]

18. Saghiri, M.A.; Asatourian, A.; Orangi, J.; Sorenson, C.M.; Sheibani, N. Functional role of inorganic trace elements in angiogenesis-Part I: N, Fe, Se, P, Au, and Ca. Crit. Rev. Oncol. Hematol. 2015, 96, 129-142. [CrossRef] 
19. Voors, A.A.; Anker, S.D.; Cleland, J.G.; Dickstein, K.; Filippatos, G.; van der Harst, P.; Hillege, H.L.; Lang, C.C.; ter Maaten, J.M.; Ng, L.; et al. A systems BIOlogy Study to TAilored Treatment in Chronic Heart Failure: Rationale, design, and baseline characteristics of BIOSTAT-CHF. Eur. J. Heart Fail. 2016, 18, 716-726. [CrossRef]

20. Voors, A.A.; Ouwerkerk, W.; Zannad, F.; van Veldhuisen, D.J.; Samani, N.J.; Ponikowski, P.; Ng, L.L.; Metra, M.; ter Maaten, J.M.; Lang, C.C.; et al. Development and validation of multivariable models to predict mortality and hospitalization in patients with heart failure. Eur. J. Heart Fail. 2017, 19, 627-634. [CrossRef]

21. Grote Beverborg, N.; Klip, I.T.; Meijers, W.C.; Voors, A.A.; Vegter, E.L.; van der Wal, H.H.; Swinkels, D.W.; van Pelt, J.; Mulder, A.B.; Bulstra, S.K.; et al. Definition of Iron Deficiency Based on the Gold Standard of Bone Marrow Iron Staining in Heart Failure Patients. Circ. Heart Fail. 2018, 11, e004519. [CrossRef]

22. Hair, J.F.; Black, W.C.; Babin, B.J.; Anderson, R.E. Multivariate Data Analysis; Prentice-Hall: Upper Saddle River, NJ, USA, 1998.

23. Hall, M.; Frank, E.; Holmes, G.; Pfahringer, B.; Reutemann, P.; Witten, I.H. The WEKA data mining software. ACM Sigkdd Explor. Newsl. 2009, 11, 10-18. [CrossRef]

24. Lewandowska, M.; Więckowska, B.; Sajdak, S.; Lubiński, J. First Trimester Microelements and Their Relationships with Pregnancy Outcomes and Complications. Nutrients 2020, 12, 1108. [CrossRef] [PubMed]

25. Arnaud, J.; Bertrais, S.; Roussel, A.M.; Arnault, N.; Ruffieux, D.; Favier, A.; Berthelin, S.; Estaquio, C.; Galan, P.; Czernichow, S.; et al. Serum selenium determinants in French adults: The SU.VI.M.AX study. Br. J. Nutr. 2006, 95, 313-320. [CrossRef] [PubMed]

26. Estruch, R.; Ros, E.; Salas-Salvadó, J.; Covas, M.-I.; Corella, D.; Arós, F.; Gómez-Gracia, E.; Ruiz-Gutiérrez, V.; Fiol, M.; Lapetra, J.; et al. Primary Prevention of Cardiovascular Disease with a Mediterranean Diet Supplemented with Extra-Virgin Olive Oil or Nuts. N. Engl. J. Med. 2018, 378, e34. [CrossRef] [PubMed]

27. Bleys, J.; Navas-Acien, A.; Guallar, E. Serum selenium levels and all-cause, cancer, and cardiovascular mortality among US adults. Arch. Intern. Med. 2008, 168, 404-410. [CrossRef]

28. Zhang, X.; Liu, C.; Guo, J.; Song, Y. Selenium status and cardiovascular diseases: Meta-analysis of prospective observational studies and randomized controlled trials. Eur. J. Clin. Nutr. 2016, 70, 162-169. [CrossRef]

29. Rayman, M.P. Dietary selenium: Time to act. BMJ 1997, 314, 387-388. [CrossRef]

30. Nève, J. New Approaches to Assess Selenium Status and Requirement. Nutr. Rev. 2000, 58, 363-369. [CrossRef]

31. Thomson, C.D.; Robinson, M.F.; Butler, J.A.; Whanger, P.D. Long-term supplementation with selenate and selenomethionine: Selenium and glutathione peroxidase (EC 1.11.1.9) in blood components of New Zealand women. Br. J. Nutr. 1993, 69, 577-588. [CrossRef]

32. Schomburg, L. The other view: The trace element selenium as a micronutrient in thyroid disease, diabetes, and beyond. Hormones 2020, 19, 15-24. [CrossRef] [PubMed]

33. Schomburg, L.; Orho-Melander, M.; Struck, J.; Bergmann, A.; Melander, O. Selenoprotein-P Deficiency Predicts Cardiovascular Disease and Death. Nutrients 2019, 11, 1852. [CrossRef] [PubMed]

34. Park, K.; Rimm, E.; Siscovick, D.; Spiegelman, D.; Steven Morris, J.; Mozaffarian, D. Demographic and lifestyle factors and selenium levels in men and women in the U.S. Nutr. Res. Pract. 2011, 5, 357-364. [CrossRef] [PubMed]

35. Alehagen, U.; Johansson, P.; Björnstedt, M.; Rosén, A.; Post, C.; Aaseth, J. Relatively high mortality risk in elderly Swedish subjects with low selenium status. Eur. J. Clin. Nutr. 2016, 70, 91-96. [CrossRef]

36. Polsinelli, V.B.; Sinha, A.; Shah, S.J. Visceral Congestion in Heart Failure: Right Ventricular Dysfunction, Splanchnic Hemodynamics, and the Intestinal Microenvironment. Curr. Heart Fail. Rep. 2017, 14, 519-528. [CrossRef]

37. Cai, Z.; Zhang, J.; Li, H. Selenium, aging and aging-related diseases. Aging Clin. Exp. Res. 2019, 31, 1035-1047. [CrossRef]

38. Alehagen, U.; Johansson, P.; Björnstedt, M.; Rosén, A.; Dahlström, U. Cardiovascular mortality and $\mathrm{N}$-terminal-proBNP reduced after combined selenium and coenzyme Q10 supplementation: A 5-year prospective randomized double-blind placebo-controlled trial among elderly Swedish citizens. Int. J. Cardiol. 2013, 167, 1860-1866. [CrossRef]

39. Yosuke, F.; Fujishima, Y.; Ohsawa, M.; Itai, K.; Kato, K.; Tanno, K.; Turin, T.C.; Onoda, T.; Endo, S.; Okayama, A.; et al. Serum Selenium Levels in Hemodialysis Patients Are Significantly Lower than Those in Healthy Controls. Blood Purif. 2011, 32, 43-47. [CrossRef] 
40. De Oña, C.G.; Martínez-Morillo, E.; González, E.G.; Argüelles, P.V.; Merayo, C.F.; Menéndez, F.V. Variation of trace element concentrations in patients undergoing hemodialysis in the north of Spain. Scand. J. Clin. Lab. Investig. 2016, 76, 492-499. [CrossRef]

41. Lai, H.; Nie, T.; Zhang, Y.; Chen, Y.; Tao, J.; Lin, T.; Ge, T.; Li, F.; Li, H. Selenium Deficiency-Induced Damage and Altered Expression of Mitochondrial Biogenesis Markers in the Kidneys of Mice. Biol. Trace Elem. Res. 2020. [CrossRef]

42. Ghashut, R.A.; McMillan, D.C.; Kinsella, J.; Vasilaki, A.T.; Talwar, D.; Duncan, A. The effect of the systemic inflammatory response on plasma zinc and selenium adjusted for albumin. Clin. Nutr. 2016, 35, 381-387. [CrossRef]

43. Bates, C.J.; Thane, C.W.; Prentice, A.; Delves, H.T. Selenium status and its correlates in a British National Diet and Nutrition Survey: People aged 65 years and over. J. Trace Elem. Med. Biol. 2002, 16, 1-8. [CrossRef]

44. Khalili, M.; Chamani, M.; Amanlou, H.; Nikkhah, A.; Sadeghi, A.A. Effects of different sources of selenium supplementation on antioxidant indices, biochemical parameters, thyroid hormones and se status in transition cows. Acta Sci. Anim. Sci. 2019, 41, 1-7. [CrossRef]

45. Gürgöze, M.K.; Ölçücü, A.; Aygün, A.D.; Taşkin, E.; Kiliç, M. Serum and hair levels of zinc, selenium, iron, and copper in children with iron-deficiency anemia. Biol. Trace Elem. Res. 2006, 111, 23-29. [CrossRef]

46. Van Nhien, N.; Khan, N.C.; Yabutani, T.; Ninh, N.X.; Kassu, A.; Huong, B.T.M.; Do, T.T.; Motonaka, J.; Ota, F. Serum levels of trace elements and iron-deficiency anemia in adult Vietnamese. Biol. Trace Elem. Res. 2006, 111, 1-9. [CrossRef]

(C) 2020 by the authors. Licensee MDPI, Basel, Switzerland. This article is an open access article distributed under the terms and conditions of the Creative Commons Attribution (CC BY) license (http://creativecommons.org/licenses/by/4.0/). 